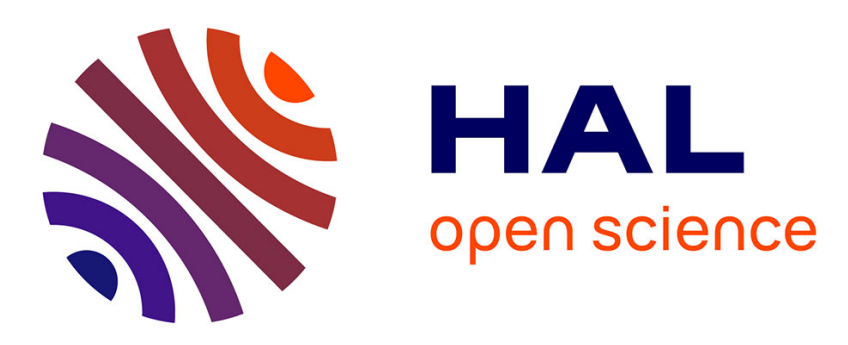

\title{
First set of microsatellite markers for genetic characterization of the Eurasian beaver () based on tissue and hair samples
}

Christiane Frosch, Peter Haase, Carsten Nowak

\section{- To cite this version:}

Christiane Frosch, Peter Haase, Carsten Nowak. First set of microsatellite markers for genetic characterization of the Eurasian beaver () based on tissue and hair samples. European Journal of Wildlife Research, 2010, pp.679-682. 10.1007/s10344-010-0486-6 . hal-00655427

\section{HAL Id: hal-00655427 https://hal.science/hal-00655427}

Submitted on 29 Dec 2011

HAL is a multi-disciplinary open access archive for the deposit and dissemination of scientific research documents, whether they are published or not. The documents may come from teaching and research institutions in France or abroad, or from public or private research centers.
L'archive ouverte pluridisciplinaire HAL, est destinée au dépôt et à la diffusion de documents scientifiques de niveau recherche, publiés ou non, émanant des établissements d'enseignement et de recherche français ou étrangers, des laboratoires publics ou privés. 


\title{
First set of microsatellite markers for genetic characterization of the Eurasian beaver (Castor fiber) based on tissue and hair samples
}

\author{
Christiane Frosch • Peter Haase • Carsten Nowak
}

Received: 4 May 2010 /Revised: 1 December 2010 /Accepted: 2 December 2010 /Published online: 29 December 2010

(C) Springer-Verlag 2010

\begin{abstract}
Noninvasive genetic techniques have become indispensible tools in wildlife conservation and management. Here, we report the development of the first set of microsatellite markers for the Eurasian beaver (Castor fiber). All 15 loci show considerable variation within the sampled region in southwestern Germany, with number of alleles ranging from two to six alleles per locus. A comparison between tissue and hair samples revealed that amplification success was only slightly lower for hair samples, making their use in noninvasive monitoring feasible. Despite some evidence for false alleles and allelic dropout, $77 \%$ of all loci were genotyped successfully among all hair samples and loci tested. The developed markers will be used for subspecies differentiation and reconstruction of dispersal routes, following reintroductions in Central Europe.
\end{abstract}

Keywords Microsatellites · Noninvasive sampling · Wildlife genetics · Eurasian beaver Castor fiber

\footnotetext{
Communicated by C. Gortázar

C. Frosch · P. Haase · C. Nowak $(\bowtie)$

Department of Limnology and Conservation, Senckenberg

Research Institutes and Natural History Museums,

Clamecystrasse 12,

63571 Gelnhausen, Germany

e-mail: cnowak@senckenberg.de

P. Haase $\cdot$ C. Nowak

Biodiversity and Climate Research Centre (BiK-F),

Senckenberganlage 25,

60325 Frankfurt am Main, Germany
}

\section{Introduction}

The Eurasian beaver, Castor fiber Linnaeus 1758, was reduced to only a few relict populations during the nineteenth century as a consequence of massive persecution (Durka et al. 2005). Because of its popularity, and the fact that beavers are key species in freshwater ecosystems (Rosell et al. 2005), considerable reintroduction efforts were started in several regions in the twentieth century (Nolet and Rosell 1998). In Central Europe, beavers were repeatedly reintroduced using source populations from different subspecies. Because of the high morphological similarity and potential interbreeding among subspecies in the field, genetic tools are needed in order to reconstruct range dynamics and long-term colonization success of reintroduced beaver populations. Mitochondrial DNA (mtDNA) markers have been shown to provide a possibility to differentiate among beavers from different subspecies (Durka et al. 2005; Ducroz et al. 2005). However, mitochondrial sequence markers provide no information concerning crossbreeding among different evolutionary lineages. In addition, published mtDNA markers do not provide sufficient resolution for safe subspecies discrimination in Germany (own data). Microsatellite markers, in contrast, enable high-resolution genetic analysis of population substructuring. While two panels of microsatellite markers exist for the Canadian beaver, Castor canadensis (Crawford et al. 2008; Pelz-Serrano et al. 2009), no microsatellites have been developed for $C$. fiber so far.

The aim of this study was to provide a genetic tool for the investigation of genetic population structure and subspecies differentiation in the Eurasian beaver. Therefore, we developed and tested a panel of variable 
microsatellite markers for this species. In order to evaluate the possibility of noninvasive sampling strategies for genetic sample collection (Taberlet et al. 1999), we compared marker performance based on both tissue and hair samples.

\section{Materials and methods}

For the construction of a genomic DNA library, we extracted DNA from a $C$. fiber albicus tissue sample from Hesse (Germany). DNA extraction of tissue samples was performed with the Qiagen Blood and Tissue Kit, following the instructions of the manufacturer. After shearing of the genomic DNA by nebulization, fragments of two size classes, namely $1.5-2.5 \mathrm{~kb}$ and $>2.5 \mathrm{~kb}$, were separated electrophoretically, electroeluted, and purified. Both groups of fragments were ligated into pUC18 vector plasmids cut with Sma I and then transformed into DA10B Escherichia coli host cells via electroporation. To identify fragments containing typical microsatellite DNA sequence motifs, 36,000 insert-containing clones were picked on gridded nitrocellulose filters (Schleicher \& Schuell, BA85) for colony filter hybridization. Clones were screened for microsatellites, using seven different radioactive labeled synthetic oligonucleotide probes $\left[(\mathrm{GA})_{15},(\mathrm{CA})_{15}\right.$, $\left.(\mathrm{AAT})_{10},(\mathrm{GGC})_{10},(\mathrm{AAG})_{10},(\mathrm{ATG})_{10},(\mathrm{GATA})_{6}\right]$. One hundred ninety-two hybridizing clones were picked at random, and their inserts were amplified by polymerase chain reaction (PCR), using standard forward and reverse vector primers.

Fifty-eight primer pairs were designed manually, or using Primer 3 (Rozen and Skaletsky 2000) and tested on eight tissue samples of mixed origin for consistent amplification success. The 10- $\mu$ l PCRs included $3.8 \mu \mathrm{l}$ of DNA extract, $1.5 \mathrm{mM} \mathrm{MgCl} 2,0.2 \mathrm{mM}$ dNTPs in equal ratio, $0.3 \mu \mathrm{M}$ of each primer, and $0.5 \mathrm{U} / \mu \mathrm{l}$ HotStarTaqPolymerase (Qiagen/Hilden). Fragments were amplified for $15 \mathrm{~min}$ at $95^{\circ} \mathrm{C}$, followed by 45 cycles of $30 \mathrm{~s}$ at $94^{\circ} \mathrm{C}, 90 \mathrm{~s}$ annealing at $50^{\circ} \mathrm{C}, 60 \mathrm{~s}$ at $72^{\circ} \mathrm{C}$, and a final elongation step of $30 \mathrm{~min}$ at $72^{\circ} \mathrm{C}$. For all PCRs, positive and negative controls were included.

Twenty-five primer pairs yielded reproducible amplicons of the correct size and were, thus, considered for fragment length analysis. Fragment length at all 25 loci were determined on a 3730 DNA Analyzer (Applied Biosystems) for 33 C. fiber individuals (17 ethanol $96 \%$ stored tissue samples from shot beavers, 12 ethanol stored samples of carcasses found in the field, 1 treated fur, 3 hair samples stored in paper envelopes at room temperature) from Hesse $(n=2)$, Rhineland-Palatinate $(n=4)$, and Bavaria $(n=27)$. We used 3-5 guard hairs or 5-15 wool hairs for hair extraction with the Investigator Kit (Qiagen), following the protocol of the manufacturer. We included negative controls in the hair-extraction process to check for cross contamination during this step. Hair samples were prepared in a separate laboratory, considering standard routines for noninvasive sample treatment to avoid cross contamination (Taberlet et al. 1999).

Genemarker 1.6 software (SoftGenetics) was used to score fragment length. Mean number of alleles per locus $(A)$, percentage of polymorphic loci $(P)$, expected $\left(H_{\mathrm{E}},\right)$ and observed $\left(H_{\mathrm{O}}\right)$ heterozygosity were calculated with GenAlex (Peakall and Smouse 2006). Hardy-Weinberg equilibrium (HWE) and linkage disequilibrium estimations were conducted using Genepop (Raymond and Rousset 1995). The suitability of the marker set for individualization of samples (Probability of Identity $=P_{(\mathrm{ID})}$ ) was calculated for an outcrossing $\left(P_{(\mathrm{ID})}\right)$ or inbred $\left(P_{(\mathrm{ID}) \mathrm{sib}}\right)$ (Paetkau and Strobeck 1994) population, using Gimlet 1.3.3 (Valiere 2002).

In order to evaluate the feasibility of noninvasive sampling methods for the beaver, we compared amplification success of hair and tissue samples, and checked for genotyping errors among hair samples. Hair and tissue samples of the same individual were analyzed from 11 of the 33 specimens considered in this study. Tissue and plucked hairs were taken from six freshly shot beavers, four cadavers, and one treated fur. Samples were genotyped at the final set of 15 microsatellite loci. Genotyping errors (allelic dropouts, false alleles) were checked manually by comparing genetic profiles based on hair samples to the respective reference genotypes obtained from tissue genotyping. For this reason, we did not conduct replicates in the hair amplification step.

\section{Results}

Of the 25 markers tested, 20 were found to be polymorphic in the test sample. Fifteen markers allowed for safe and consistent genotyping, and were thus considered for the final marker set (Table 1). The observed number of alleles per locus of the final marker set ranged from two to six, with observed heterozygosity values ranging from 0.24 to 0.77. Significant linkage disequilibrium (Fisher's exact test, $p<0.05)$ was revealed for nine combinations of loci. However, none were significant following Bonferroni correction. A significant heterozygote deficit was observed for three loci (CF06, CF18, CF49; Exact HW test; Guo and Thompson 1992). Calculated values for the probability of identity of the marker set were $P_{(\mathrm{ID})}=4.23 \times 10^{-9}$, and $P_{(\mathrm{ID})}$ $\mathrm{sib}=1.13 \times 10^{-4}$ for an inbred population.

Amplification success of hair samples was significantly lower compared to tissue samples (one-tailed paired $t$-test, $p<0.001)$. Comparison of amplification success in 11 
Table 1 Primer sequences and characterization of 15 variable microsatellite loci for the Eurasian beaver, Castor fiber ( $n=33)$

\begin{tabular}{|c|c|c|c|c|c|c|}
\hline Locus & Accession no. & Sequence $\left(5^{\prime}-3^{\prime}\right)$ & Motif & $\mathrm{N}_{\mathrm{A}}$ & Range (bp) & $\mathrm{H}_{\mathrm{O}} / \mathrm{H}_{\mathrm{E}}$ \\
\hline CF05 & HQ698339 & GGAAATATTTAAAGGGTCGAATG TTGCAGTTTCTTGGAACACG & $(\mathrm{TG})_{15}$ & 2 & $213-215$ & $0.33 / 0.48$ \\
\hline CF06 & HQ698340 & TGTGGCCTGTAATACGAAAAG TCAGATGTTCAAGACCACCAA & $(\mathrm{GT})_{14}$ & 3 & $134-141$ & $0.39 / 0.66^{* *}$ \\
\hline $\mathrm{CF} 07$ & HQ698341 & CTTTTGCCACACTCAACACAA TTCCTAGGCAGAAATCAGGAA & $(\mathrm{AC})_{10}$ & 3 & $92-96$ & $0.35 / 0.59^{*}$ \\
\hline CF17 & HQ698342 & CCAAGAGGGCTGTCTCATGT CGTTGTGCTTGCTAGGTGAG & $(\mathrm{GT})_{13}$ & 4 & $196-219$ & $0.41 / 0.57^{*}$ \\
\hline CF18 & HQ698343 & TGTCTCCCAAATGGACTTCA CCGTCTTCAAGCCATAAACC & $(\mathrm{AC})_{15}$ & 4 & $212-218$ & $0.24 / 0.45^{* *}$ \\
\hline CF19 & HQ698344 & AGTGGGCTGCCATTGTTAAG TCTGCACAGTGTTCATGCTG & $(\mathrm{CA})_{16}$ & 2 & $186-188$ & $0.42 / 0.33$ \\
\hline CF21 & HQ698345 & CATGGGGTGGGGGTATTATC ATCCTTTCTTGGTCCTGCAA & $(\mathrm{TG})_{9}$ & 3 & $197-205$ & $0.46 / 0.51^{*}$ \\
\hline CF30 & HQ698346 & GCCCATGCTCTCAGCATTAT TGCGCACATGTATATGACTCAC & $(\mathrm{AC})_{17}$ & 4 & $212-222$ & $0.62 / 0.48$ \\
\hline CF31 & HQ698347 & TCCCTCAGGCTTTAATTGGA TCTCGAGCCCCTATCTTGAA & $(\mathrm{GT})_{22}$ & 4 & $193-203$ & $0.64 / 0.58^{*}$ \\
\hline CF32 & HQ698348 & CAGTTTTGTTCTCTCTCTCACTATGAA GGCTCAAAAAGTCAAAGGTCA & $(\mathrm{TG})_{16}$ & 3 & $130-138$ & $0.60 / 0.51$ \\
\hline CF33 & HQ698349 & TGCCACCCTAACAAATAGGTG GTTTTGCTCATCAGCCCTGT & $(\mathrm{TG})_{20}$ & 6 & $202-222$ & $0.77 / 0.71$ \\
\hline CF41 & HQ698350 & CAACCACTCCCACCCACTC TGTCTGCCTGGTAAGCATGA & $(\mathrm{CA})_{17}$ & 3 & $102-107$ & $0.57 / 0.64^{* *}$ \\
\hline CF44 & HQ698351 & GGGGAAAGGGAGAGGAGTTT TAATCCTATCCCCCAAGTCG & $(\mathrm{TG})_{20}$ & 4 & $203-211$ & $0.59 / 0.66$ \\
\hline CF48 & HQ698352 & AGTGGTTGCCCAAAATGAAC GGAGTGGCTTAAGGTGTTCG & $(\mathrm{GT})_{13}$ & 3 & 191-199 & $0.71 / 0.48$ \\
\hline CF49 & HQ698353 & GTGCCCAGCATCGAGAAGTA CCCCTCTGCTGTGTGCTAGT & $(\mathrm{CA})_{7}$ & 3 & $130-141$ & $0.69 / 0.53^{* *}$ \\
\hline
\end{tabular}

$N_{\mathrm{A}}$ Number of alleles, $H_{\mathrm{O}}$ Observed Heterozygosity, $H_{\mathrm{E}}$ Expected Heterozygosity. Significant departures from Hardy-Weinberg equilibrium $(p<0.05)$ are indicated before $\left(^{*}\right)$ and after $\left(^{* *}\right)$ Bonferroni correction

samples resulted in 9-11 successfully amplified fragments per locus for tissue and 5-10 successful PCR reactions based on hair extractions (Table 2). Genotyping errors in hair samples were detected at two loci (CF33 and CF48).

Table 2 Amplification success (defined as presence of scorable fragments within the expected size range in the fragment length analysis; +PCR) of 15 microsatellite loci based on hair and tissue samples from 11 Castor fiber individuals and the number of correct genotypes obtained from hair samples (+genotype)

\begin{tabular}{lccc}
\hline Locus & +PCR (tissue) & +PCR (hairs) & +Genotype (hairs) \\
\hline CF05 & $9 / 11$ & $9 / 11$ & $9 / 9$ \\
CF06 & $11 / 11$ & $9 / 11$ & $9 / 11$ \\
CF07 & $7 / 11$ & $7 / 11$ & $7 / 7$ \\
CF17 & $11 / 11$ & $9 / 11$ & $9 / 11$ \\
CF18 & $10 / 11$ & $7 / 11$ & $7 / 10$ \\
CF19 & $11 / 11$ & $8 / 11$ & $8 / 11$ \\
CF21 & $10 / 11$ & $10 / 11$ & $10 / 10$ \\
CF30 & $11 / 11$ & $10 / 11$ & $10 / 11$ \\
CF31 & $9 / 11$ & $7 / 11$ & $7 / 9$ \\
CF32 & $11 / 11$ & $7 / 11$ & $7 / 11$ \\
CF33 & $11 / 11$ & $9 / 11$ & $5 / 11^{\text {ab }}$ \\
CF41 & $11 / 11$ & $9 / 11$ & $9 / 11$ \\
CF44 & $10 / 11$ & $5 / 11$ & $5 / 10$ \\
CF48 & $11 / 11$ & $8 / 11$ & $7 / 11^{\mathrm{b}}$ \\
CF49 & $11 / 11$ & $9 / 11$ & $9 / 11$ \\
\hline
\end{tabular}

${ }^{\mathrm{a}}$ false alleles, ${ }^{\mathrm{b}}$ allelic drop out

\section{Discussion}

Here, we provide 15 novel variable markers, which can be easily multiplexed due to a harmonization of reaction conditions. Along with moderate $\mathrm{H}_{\mathrm{E}}$ levels, only few different alleles were found at most loci. We are not able to decide here, however, if these rather low levels of genetic variability are due to genetic homogeneity of the reintroduced beaver populations or a characteristic of the marker system itself. Despite of the moderate diversity levels per locus, $\mathrm{P}_{(\mathrm{ID})}$ and $\mathrm{PID}_{(\mathrm{ID}) \text { sib }}$ values show that even for an inbred population, the marker system is well suitable for individual identification with a high statistical confidence. Due to the fact that our samples were collected from across Southern Germany, revealed deviations from HWE at three loci are likely caused by population substructuring.

In a cross-species amplification test, Pelz-Serrano et al. (2009) identified nine microsatellite markers developed for the Canadian beaver, which showed variation within $C$. fiber. Of these markers, however, only four (Cca4, Cca13, Cca18, Cca92) were variable among our 33 samples (data not shown). Along with these loci, the presented markers will be used to differentiate among $C$. fiber subspecies and to reconstruct the contribution of different founder populations to the currently observed recolonization success in Southern Germany. As amplification failure and genotyping error for hair samples was rather low, we recommend the use of beaver hair trapping in order to allow for increased sample sizes and a standardized sampling design. 
Acknowledgments We are grateful to all the beaver managers in Germany for kindly providing us samples. Genomic microsatellite identification was performed by GENterprise Genomics, Mainz, Germany. The study was funded by the Regierungspräsidium Darmstadt, federal state of Hesse. Additional funding was provided by the Hessian initiative for scientific and economic excellence (LOEWE - Landes-Offensive zur Entwicklung wissenschaftlichökonomischer Exzellenz) of the Hessian Ministry of Higher Education, Research, and the Arts.

Declaration The authors of this manuscript declare that all experiments performed in this study comply with the current laws in Germany. Furthermore, we declare that we have no conflict of interest concerning the published data.

\section{References}

Crawford J, Liu Z, Nelson T, Nielsen C, Bloomquist C (2008) Isolation and characterization of microsatellite loci in the beaver (Castor canadensis). Mol Ecol Resources 8:616-618. doi:10.1111/j.1471-8286.2007.02016.x

Ducroz J-F, Stubbe M, Saveljev AP, Heidecke D, Samjaa R, Ulevičius A, Stubbe A, Durka W (2005) Genetic variation and population structure of the Eurasian beaver Castor fiber in Eastern Europe and Asia. J Mammal 86:1059-1067. doi:10.1644/1545-1542 (2005)86[1059:GVAPSO]2.0.CO;2

Durka W, Babik W, Ducroz JF, Heidecke D, Rosell F, Samjaa R, Saveljev AP, Stubbe A, Ulevicius A, Stubbe M (2005) Mitochondrial phylogeography of the Eurasian beaver Castor fiber L. Mol Ecol 14:3843-3856. doi:10.1111/j.1365-294X.2005.02704.x
Guo SW, Thompson EA (1992) Performing the exact test of HardyWeinberg proportions for multiple alleles. Biometrics 48:361372. doi: $10.2307 / 2532296$

Nolet BA, Rosell F (1998) Come back of the beaver Castor fiber: an overview of old and new conservation problems. Biol Conserv 83:165-173. doi:10.1016/S0006-3207(97)00066-9

Paetkau D, Strobeck C (1994) Microsatellite analysis of genetic variation in black bear populations. Mol Ecol 3:489-495. doi:10.1111/j.1365-294X.1994.tb00127.x

Peakall R, Smouse PE (2006) Genalex 6: genetic analysis in Excel. Population genetic software for teaching and research. Mol Ecol Notes 6:288-295. doi:10.1111/j.1471-8286.2005.01155.x

Pelz-Serrano K, Munguia-Vega A, Piaggio AJ, Neubaum M, Munclinger P, Pártl A, van Riber C, Culver M (2009) Development of nine new microsatellite loci for the American beaver, Castor canadensis (Rodentia: Castoridae), and cross-species amplification in the European beaver, Castor fiber. Mol Ecol Resources 9:551-554. doi:10.1111/j.1755-0998.2008.02364.x

Raymond M, Rousset F (1995) Genepop (version- 1.2) - Population Genetics Software for exact tests and ecumenicism. J Hered $86: 248-249$

Rosell F, Bozsér O, Collen P, Parker H (2005) Castor fiber and Castor canadensis and their ability to modify ecosystems. Mamm Soc 35:248-276. doi:10.1111/j.1365-2907.2005.00067.x

Rozen S, Skaletsky HJ (2000) Primer3 on the WWW for general users and for biologist programmers. In: Krawetz S, Misener S (eds) Bioinformatics methods and protocols: methods in molecular biology. Humana Press, Totowa, pp 365-386

Taberlet P, Waits LP, Luikart G (1999) Noninvasive genetic sampling: look before you leap. Trends Ecol Evol 4:323-327. doi:10.1016/ S0169-5347(99)01637-7

Valiere N (2002) gimlet: a computer program for analysing genetic individual identification data. Mol Ecol Notes 2:377-379. doi:10.1046/j.1471-8286.2002.00228.x 